\title{
Подавление волноводной рекомбинации за счет использования парных асимметричных барьеров в лазерных гетероструктурах
}

\author{
(С) Ф.И. Зубов ${ }^{1}$, М.В. Максимов ${ }^{1,2}$, Н.Ю. Гордеев ${ }^{2,1}$, Ю.С. Полубавкина ${ }^{1}$, А.Е. Жуков ${ }^{1}$ \\ ${ }^{1}$ Санкт-Петербургский национальный исследовательский Академический университет \\ Российской академии наук, \\ 194021 Санкт-Петербург, Россия \\ ${ }^{2}$ Физико-технический институт им. А.Ф. Иоффе Российской академии наук, \\ 194021 Санкт-Петербург, Россия \\ E-mail: fedyazu@mail.ru
}

(Получена 3 июля 2017 г. Принята к печати 10 июля 2017 г.)

\begin{abstract}
Предложена конструкция полупроводникового лазера, в котором за счет использования парных асимметричных барьеров, прилегающих к активной области, подавляется паразитная волноводная рекомбинация. Парные асимметричные барьеры блокируют нежелательный транспорт носителей заряда одного типа, не препятствуя распространению носителей другого типа. Спейсер, разделяющий парные асимметричные барьеры, может служить для компенсации вносимых ими упругих напряжений, а также управления энергетическим спектром носителей заряда и соответственно коэффициентом пропускания. На примере лазера с волноводными слоями $\mathrm{Al}_{0.2} \mathrm{Ga}_{0.8} \mathrm{As}$ показано, что за счет использования конструкции парных асимметричных барьеров нежелательный транспорт электронов может быть подавлен в 4 раза в сравнении со случаем использования одиночного асимметричного барьера.
\end{abstract}

DOI: 10.21883/FTP.2018.02.45453.8675

\section{1. Введение}

Паразитная рекомбинация носителей заряда в волноводных слоях полупроводниковых лазеров является одной из ключевых проблем инжекционных лазеров на основе гетероструктур традиционной конструкции с волноводным слоем постоянного состава [1]. Одновременное заселение волноводного слоя электронами и дырками приводит к росту порогового тока, снижению эффективности лазерной генерации, снижению кпд прибора, сублинейному росту выходной оптической мощности свыше порога лазерной генерации [2-4]. Паразитная рекомбинация также является причиной высокой чувствительности характеристик прибора к изменениям окружающей температуры, так как соответствующая составляющая тока накачки экспоненциально зависит от температуры.

Наиболее остро проблема паразитной рекомбинации стоит в случае использования конструкции лазерной гетероструктуры с малой энергией локализации носителей заряда в активной области [5], что характерно для коротковолновых лазеров. Проблема паразитной рекомбинации также характерна для лазеров с широким волноводным слоем (0.5 мкм и более), в условиях генерации при повышенной окружающей температуре $\left(60^{\circ} \mathrm{C}\right.$ и более), а также в режиме высоких плотностей тока накачки (1 кА/см² и более). Обычно такие условия характерны для мощных коротковолновых лазеров (с длиной волны излучения 1 мкм и менее), используемых для обработки материалов (резка, сварка металлов), накачки твердотельных лазеров, в экспериментах по разогреву термоядерной плазмы, в системах обнаружения и определения дальности (лидарах).

Наиболее прямой способ подавления паразитной рекомбинации - использование материалов волноводных слоев с большей шириной запрещенной зоны [6]. Однако этот способ не всегда применим вследствие ограничений, накладываемых согласованием кристаллических решеток, и наличием материалов с подходящим положением краев энергетических зон. Другой недостаток такого подхода - увеличение ширины запрещенной зоны волновода приводит к снижению контраста показателя преломления волновода и обкладок и, как следствие, к снижению фактора оптического ограничения.

В тех случаях, когда реализация волновода с большой шириной запрещенной зоны невозможна, альтернативным решением для подавления биполярного заселения матрицы может быть использование тонких, толщиной несколько нанометров, слоев асимметричных барьеров (АБ), прилегающих к активной области по обе стороны (рис. 1) [7,8]. Материалы таких слоев могут быть подо-

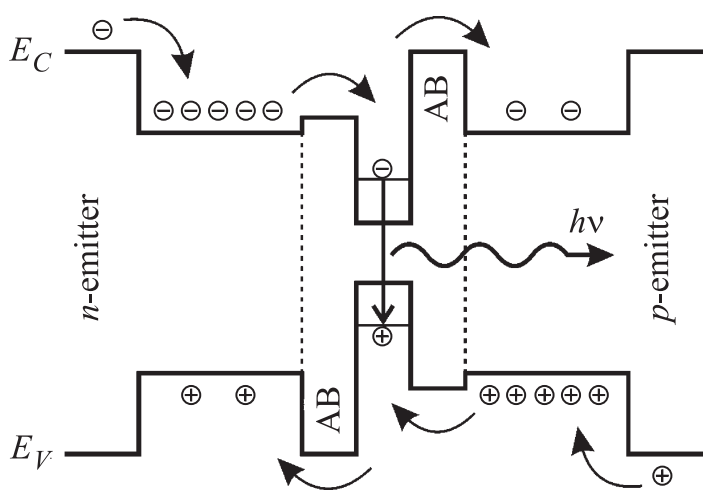

Рис. 1. Схематичная зонная энергетическая диаграмма лазерной гетероструктуры с двумя одиночными АБ слоями (отмечены как $\mathrm{AB}$ ). 
браны так, чтобы в зоне проводимости (валентной зоне) матрицы образовывался высокий потенциальный барьер, препятствующий транспорту электронов (дырок), тогда как, наоборот, в валентной зоне (зоне проводимости) разрыв зоны на интерфейсе АБ/волновод либо отсутствовал, либо не сказывался на распространении дырок (электронов) [9]. При этом ввиду малой толщины слои АБ могут быть синтезированы в псевдоморфном режиме даже при некоторой рассогласованности по параметру решетки относительно подложки. В идеальном случае, когда АБ полностью блокируют нежелательный транспорт, область сосуществования электронов и дырок ограничена активной областью и паразитная рекомбинация в волноводе отсутствует [10].

Для $\mathrm{AlGaAs} / \mathrm{GaAs}$-лазеров, использующих такую конструкцию на основе АБ, было обнаружено уменьшение порогового тока, увеличение характеристической температуры [11], а также наблюдалось некоторое увеличение эффективности лазерной генерации [12]. Тем не менее выбор соединений с необходимой асимметрией барьеров и(или) их толщин также сильно ограничен ввиду рассогласования слоев по постоянной решетке при использовании традиционных полупроводниковых твердых растворов (AlGaInAsP). В особенности это вызывает трудности при проектировании АБ, расположенного со стороны $p$-эмиттера в лазерных гетероструктурах $\mathrm{AlGaAs/GaAs.} \mathrm{При} \mathrm{выборе} \mathrm{высоты} \mathrm{и} \mathrm{толщины} \mathrm{барье-}$ ра необходим компромисс для обеспечения условий псевдоморфного синтеза. Поэтому АБ не может быть создан одновременно достаточно высоким и достаточно толстым, как это требуется для более полного подавления туннельного прохождения частиц и надбарьерной инжекции [13].

На практике улучшение приборных характеристик оказалось намного менее значительным в сравнении с тем, что ожидалось для случая полного подавления волноводной рекомбинации [14]. Как было установлено в результате исследования $\mathrm{AlGaAs} / \mathrm{GaAs}$-лазерных структур с АБ методом оптической ближнепольной микроскопии [15], это связано с проникновением электронов в область волновода, примыкающую к $p$-эмиттеру вследствие неполного блокирования электронного транспорта соответствующим АБ.

В настоящей работе рассматривается конструкция инжекционного лазера, включающего два асимметричных барьера по обе стороны активной области, из которых по крайней мере один представляет собой комбинацию из двух АБ слоев, разделенных спейсерным слоем. Показано, что в такой конструкции может быть достигнуто значительно более полное подавление биполярной заселенности по сравнению с одиночным АБ.

\section{2. Лазер с парными асимметричными барьерами}

Предлагаемая конструкция лазера с парными АБ проиллюстрирована на рис. 2. Между волноводными сло-

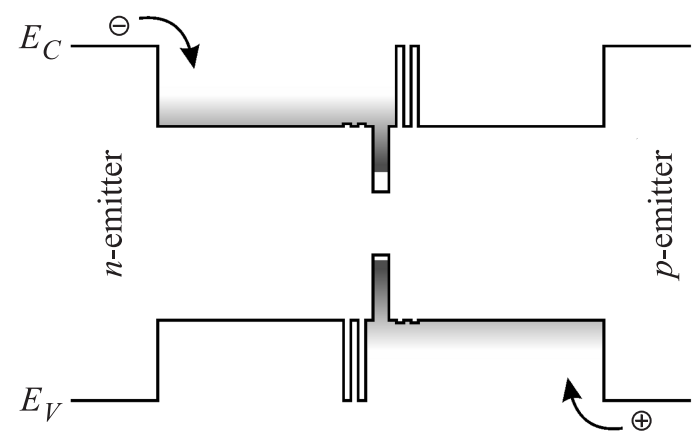

Рис. 2. Схематичная зонная энергетическая диаграмма лазерной гетероструктуры с двумя парными АБ слоями.

ями, ограниченными $n$ - и $p$-эмиттерами, располагается активная область (например, квантовая яма) и два АБ, заключающие между собой активную область. АБ, расположенный относительно активной области со стороны p-эмиттера, является парным АБ, состоящим из двух АБ слоев, разделенных спейсерным слоем. Каждый из АБ слоев, входящих в состав парного АБ, характеризуется малой ( $k T$ или менее; $k T$ - тепловая энергия) высотой потенциального барьера, образующегося в валентной зоне на гетерогранице с примыкающим к $p$-эмиттеру волноводным слоем, и большой высотой (более $2 k T$, предпочтительно более $3 k T$ ) потенциального барьера в зоне проводимости на гетерогранице с примыкающим к $p$-эмиттеру волноводным слоем. Толщина каждого из АБ слоев в отдельности не превосходит критическую толщину псевдоморфного роста и выбирается с учетом величины рассогласования кристаллической решетки этого слоя по отношению к подложке.

Конструкция и принцип действия парного АБ, расположенного со стороны $n$-эмиттера, аналогичны. Однако для лазеров на основе материалов $\mathrm{AlGaAs} / \mathrm{GaAs}$ может быть создан очень высокий потенциальный барьер (более 200 мэВ) для дырок с использованием твердого раствора GaInP [11], так что для этой системы материалов большой необходимости в использовании парного АБ со стороны $n$-эмиттера нет. В связи с этим далее нами будет рассмотрена конструкция лазерной гетероструктуры, содержащей двойной барьер в зоне проводимости.

Предпочтительно выбирать химический состав спейсера таким образом, чтобы его положение края валентной зоны приблизительно соответствовало положению края валентной зоны АБ слоев. Таким образом, не создается дополнительного барьера для инжекции дырок из $p$-эмиттера в активную область через слои парного АБ.

Принципиальное отличие двухбарьерной конструкции, предлагаемой в настоящей работе для подавления нежелательного транспорта носителей заряда, в сравнении с конструкцией лазера, использующей одиночный АБ, возможность управлять разрешенным спектром энергетических состояний носителей. Спейсер, расположенный между двумя АБ слоями одного парного АБ, имеет 
нанометровую толщину (около 10 нм), что приводит к квантованию энергетических уровней. В результате имеет место преимущественно резонансное туннелирование носителей сквозь структуру, т.е. только тех носителей, энергия которых близка к квазиуровню размерного квантования, тогда как туннельное прохождение носителей заряда всех прочих энергий подавлено. Это приводит к более существенному подавлению выброса носителей заряда из активной области в волноводные слои по сравнению с использованием одиночных барьерных слоев.

В том случае, если материал спейсера согласован по постоянной кристаллической решетки с подложкой, предельная суммарная толщина двух АБ приблизительно равна критической толщине одиночного слоя такого же химического состава, который может быть осажден в псевдоморфном режиме. Поэтому более предпочтительным представляется использование спейсера, который имеет знак рассогласования, противоположный знаку рассогласования материала АБ слоев. Благодаря компенсации упругих напряжений в этом варианте конструкции суммарная толщина АБ слоев может заметно превосходить толщину одиночного слоя такого же химического состава, который мог бы быть осажден в псевдоморфном режиме без использования спейсера.

Компенсация упругих напряжений также предоставляет больше возможностей при выборе материалов для АБ слоев и позволяет увеличить не только их толщину, но и степень асимметрии образуемых ими потенциальных барьеров для более существенного подавления надбарьерного теплового переброса носителей заряда.

\section{3. Примеры парных асимметричных барьеров}

Далее рассмотрены два варианта парных АБ, и представлены результаты расчетов потоков носителей сквозь них. В первом варианте материал спейсера согласован с подложкой, а во втором спейсер компенсирует упругие напряжения, вносимые слоями АБ.

В качестве реперной лазерной конструкции с одиночными АБ рассмотрим гетероструктуру с волноводом $\mathrm{Al}_{0.2} \mathrm{Ga}_{0.8} \mathrm{As}$, описанную в работе [11]. Со стороны $n$-эмиттера синтезировался АБ слой $\mathrm{Ga}_{0.55} \operatorname{In}_{0.45} \mathrm{P}$ толщиной 5 нм, который в валентной зоне образует основной энергетический барьер высотой 240 мэВ, тогда как высота побочного барьера в зоне проводимости всего 1 мэВ. Этот слой имеет рассогласование - $0.25 \%$ относительно подложки. АБ слой со стороны $p$-эмиттера

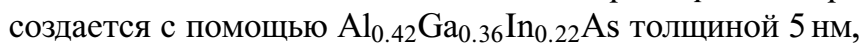
формирующего для электронов разрыв зон 69 мэВ, a для дырок - 25 мэВ; величина рассогласования составляет $1.63 \%$.

На рис. 3 показана расчетная величина потока носителей заряда через АБ $\mathrm{Ga}_{0.55} \mathrm{In}_{0.45} \mathrm{P}$ при комнатной температуре в зависимости от его толщины, рассчитанная с помощью формулы Тсу-Есаки [16]. Поток нормирован на величину потока электронов через барьер толщиной

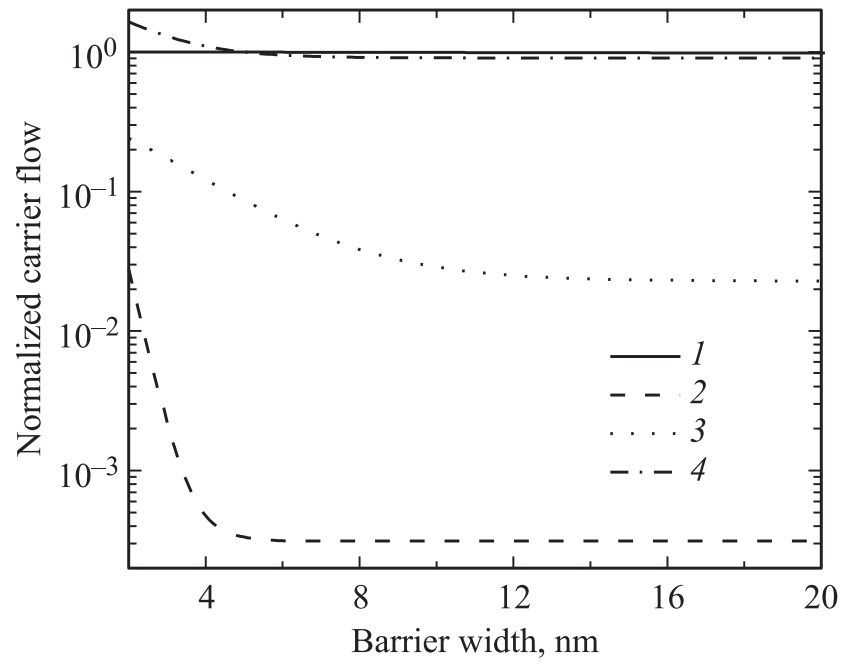

Рис. 3. Потоки электронов (1) и дырок (2) через одиночный АБ $\mathrm{Ga}_{0.55} \mathrm{In}_{0.45}$ Р в зависимости от его ширины, нормированные на величину потока электронов через такой барьер толщиной 5 нм. Также показаны потоки электронов (3) и дырок (4) через одиночный АБ $\mathrm{Al}_{0.42} \mathrm{Ga}_{0.36} \operatorname{In}_{0.22} \mathrm{As}$ в зависимости от его ширины, нормированные на величину потока дырок через такой барьер толщиной 5 нм.

5 нм. Как видно, при такой толщине одиночного АБ, как в реперной конструкции, поток дырок более чем на 3 порядка меньше потока электронов. Таким образом, такой барьер обладает высокой степенью асимметрии пропускания носителей заряда разного типа - он существенно затрудняет выброс дырок из активной области в волноводный слой, не препятствуя инжекции электронов из эмиттера в активную область. При увеличении толщины АБ свыше 5 нм ни поток электронов, ни поток дырок через барьер практически не изменяются. Следовательно, не имеет смысла увеличивать толщину этого АБ.

На рис. 3 также показана расчетная величина потока носителей заряда через АБ $\mathrm{Al}_{0.42} \mathrm{Ga}_{0.36} \operatorname{In}_{0.22} \mathrm{As}$ при комнатной температуре в зависимости от толщины АБ слоя. Поток нормирован на значение, соответствующее потоку дырок через барьер толщиной 5 нм. Как видно, при такой толщине одиночного АБ, как в реперной конструкции, поток электронов остается довольно большим (примерно в 10 раз меньше потока дырок). Таким образом, такой барьер обладает невысокой степенью асимметрии пропускания относительно носителей заряда разного типа - хотя он и не препятствует инжекции дырок из эмиттера в активную область, он лишь незначительно затрудняет выброс электронов из активной области в волноводный слой. При увеличении толщины АБ свыше 5 нм поток электронов заметно снижается (примерно в 4 раза при толщине барьера 15 нм). Следовательно, было бы желательно увеличить толщину этого АБ для более полного подавления выброса электронов из активной области и, как результат, более полного подавления паразитной волноводной рекомбинации. При этом поток дырок через барьер практически не изменяется, что 


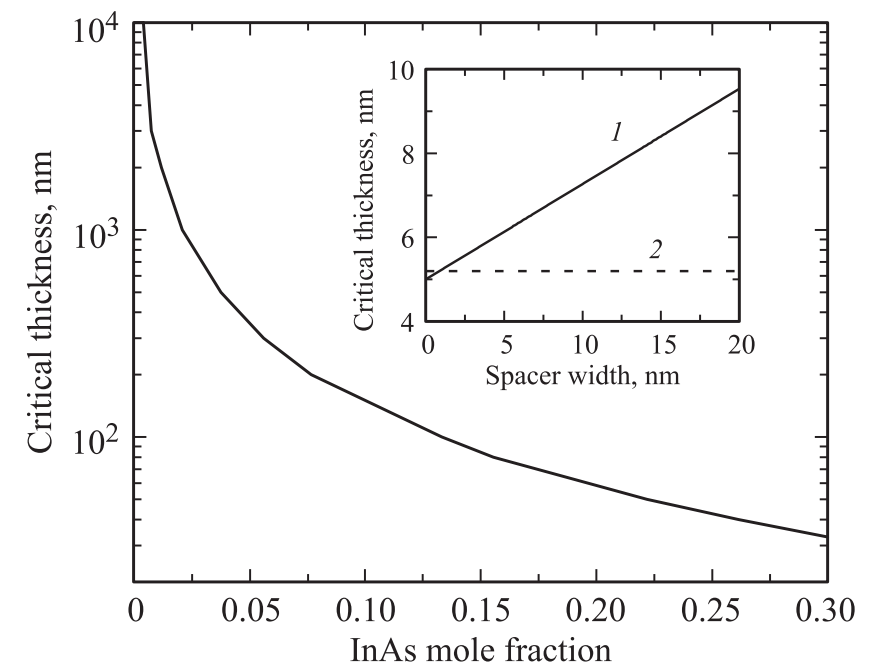

Рис. 4. Критическая толщина In-содержащих твердых растворов AlGaInAs при осаждении на подложку GaAs в зависимости от мольной доли In. На вставке - максимальная суммарная толщина АБ слоев $\mathrm{Al}_{0.42} \mathrm{Ga}_{0.36} \operatorname{In}_{0.22} \mathrm{As}$ (1), которая не приводит к формированию дислокаций несоответствия в парном АБ $\mathrm{Al}_{0.42} \mathrm{Ga}_{0.36} \mathrm{In}_{0.22} \mathrm{As}_{\mathrm{Al}} / \mathrm{Al}_{0.21} \mathrm{Ga}_{0.79} \mathrm{As}_{0.9} \mathrm{P}_{0.1} / \mathrm{Al}_{0.42} \mathrm{Ga}_{0.36} \mathrm{In}_{0.22} \mathrm{As} \mathrm{c}$ учетом компенсации упругих напряжений за счет использования спейсера $\mathrm{Al}_{0.21} \mathrm{Ga}_{0.79} \mathrm{As}_{0.9} \mathrm{P}_{0.1}$, в зависимости от толщины спейсерного слоя; также показана критическая толщина слоя $\mathrm{Al}_{0.42} \mathrm{Ga}_{0.36} \operatorname{In}_{0.22} \mathrm{As}(2)$, синтезированного на подложке $\mathrm{GaAs}$.

означает, что более толстый барьер не будет создавать дополнительного препятствия для инжекции дырок.

На рис. 4 показана зависимость критической толщины - предельной толщины слоя AlGaInAs, который может быть осажден без образования дислокаций в зависимости от мольной доли индия согласно [17]. Как видно, для содержания индия 0.22 , что соответствует материалу АБ слоя в реперной конструкции, критическая толщина составляет около 5.2 нм. Следовательно, практически отсутствует возможность увеличения толщины одиночного АБ слоя выше той величины, которая была использована в реперной лазерной структуре.

В первом варианте предлагаемой конструкции в качестве парного АБ используется комбинация $\mathrm{Al}_{0.42} \mathrm{Ga}_{0.36} \mathrm{In}_{0.22} \mathrm{As}_{/} \mathrm{Al}_{0.25} \mathrm{Ga}_{0.75} \mathrm{As} / \mathrm{Al}_{0.42} \mathrm{Ga}_{0.36} \mathrm{In}_{0.22} \mathrm{As}$. Поскольку материал спейсера $\mathrm{Al}_{0.25} \mathrm{Ga}_{0.75} \mathrm{As}$ согласован по параметру кристаллической решетки с подложкой GaAs, толщина каждого из двух АБ слоев выбрана 2.5 нм, так что их суммарная толщина не превосходит критическую толщину псевдоморфного роста. Положение края валентной зоны в материале спейсера приблизительно совпадает с положением края валентной зоны в АБ слоях. Положение края зоны проводимости в материале спейсера примерно на 46 мэВ выше края зоны проводимости в материале волноводного слоя $\mathrm{Al}_{0.2} \mathrm{Ga}_{0.8} \mathrm{As}$.

На рис. 5 показана расчетная величина потока носителей заряда при комнатной температуре через парный АБ конструкции первого варианта в зависимости от толщины $\left(d_{s p}\right)$ спейсера. Поток нормирован на значение, соответствующее потоку дырок через одиночный барьер $\mathrm{Al}_{0.42} \mathrm{Ga}_{0.36} \mathrm{In}_{0.22} \mathrm{As}$ толщиной 5 нм. Как видно, начиная с $d_{s p}=8$ нм поток электронов дополнительно снижается примерно в 2 раза по сравнению со случаем одиночного АБ реперной конструкции, что связано с эффектом подавления туннелирования электронов сквозь парный потенциальный барьер. При этом поток дырок практически не изменяется. Таким образом, использование парного АБ позволяет более полно подавить выброс электронов из активной области без ухудшения свойств инжекции дырок в активную область.

Второй вариант конструкции парного АБ отличается от рассмотренного выше первого варианта тем, что в ней входящий в состав парного АБ спейсер не согласован с подложкой и имеет знак рассогласования, противоположный знаку рассогласования материала АБ слоев. В качестве материала АБ слоев нами так же, как и в первом варианте, был рассмотрен четверной твердый раствор $\mathrm{Al}_{0.42} \mathrm{Ga}_{0.36} \mathrm{In}_{0.22} \mathrm{As}$. В качестве материала спейсера используется четверной твердый раствор $\mathrm{Al}_{0.21} \mathrm{Ga}_{0.79} \mathrm{As}_{0.9} \mathrm{P}_{0.1}$, величина рассогласования которого относительно подложки составляет $-0.35 \%$. Положение края валентной зоны в материале спейсера приблизительно совпадает с положением края валентной зоны в АБ слоях. Положение края зоны проводимости в материале спейсера примерно на 65 мэВ выше края зоны проводимости в материале волноводного слоя.

Толщина каждого из АБ слоев в отдельности взята равной 4 нм, так что суммарная толщина двух АБ превосходит толщину одиночного слоя такого же химического состава, который может быть осажден в псевдоморфном режиме. На вставке к рис. 4 показана максимальная суммарная толщина пары АБ слоев, которая не приводит к формированию дислокаций несоответствия в

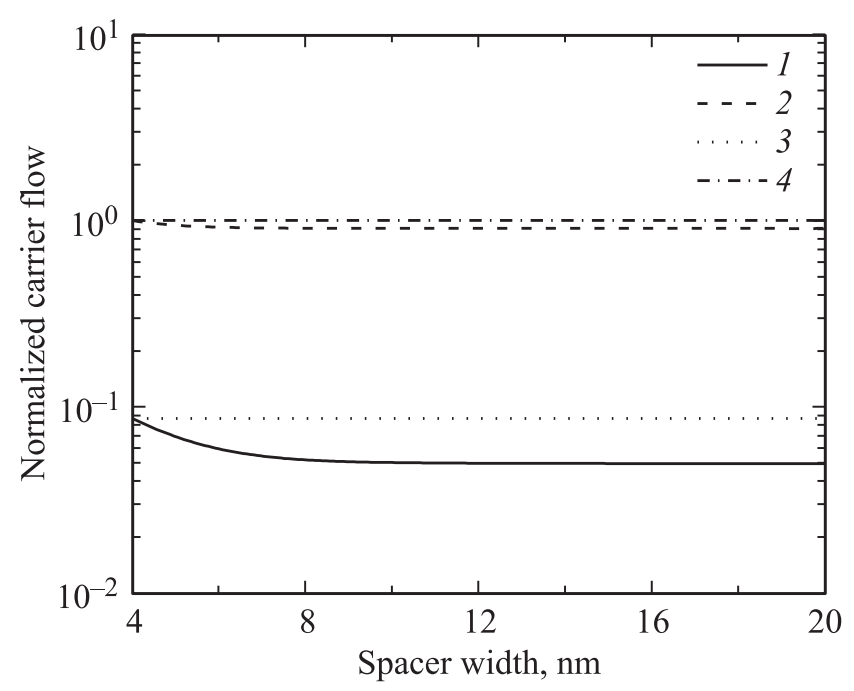

Рис. 5. Потоки электронов (1) и дырок (2) через парный АБ конструкции первого варианта в зависимости от ширины спейсера. Также показаны потоки электронов (3) и дырок (4) через реперный одиночный АБ $\mathrm{Al}_{0.42} \mathrm{Ga}_{0.36} \mathrm{In}_{0.22} \mathrm{As}$ шириной 5 нм. Потоки нормированы на поток дырок через реперный АБ. 


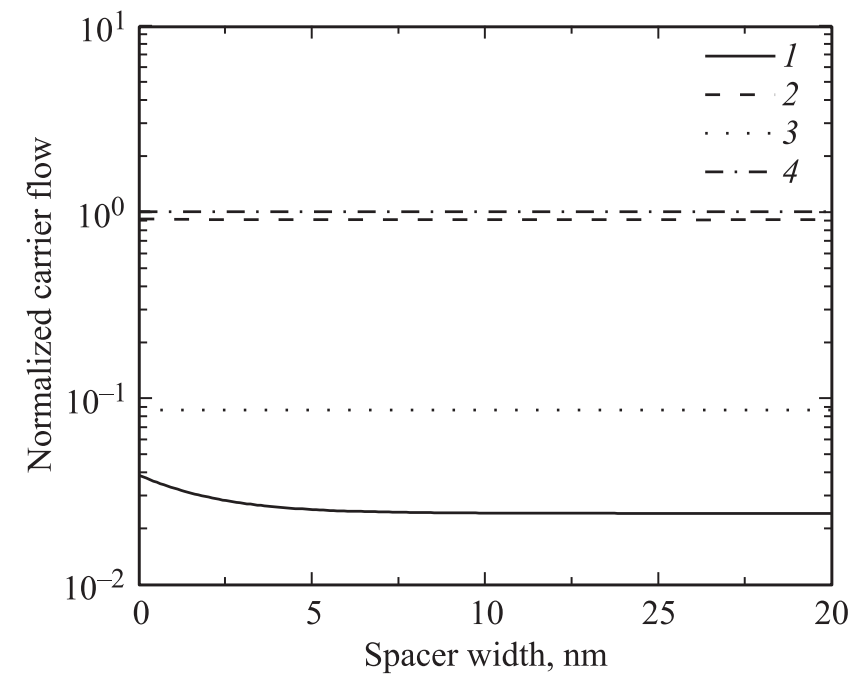

Рис. 6. Потоки электронов (1) и дырок (2) через парный АБ конструкции второго варианта в зависимости от ширины спейсера. Также показаны потоки электронов (3) и дырок (4) через реперный одиночный $\mathrm{AБ} \mathrm{Al}_{0.42} \mathrm{Ga}_{0.36} \operatorname{In}_{0.22} \mathrm{As}$ шириной 5 нм. Потоки нормированы на поток дырок через реперный АБ.

АБ в целом с учетом компенсации упругих напряжений за счет использования спейсера противоположного знака рассогласования в зависимости от величины $d_{s p}$. Как видно, для того чтобы суммарная толщина АБ слоев могла составлять 8 нм, толщина спейсера должна превышать 13.3 нм.

На рис. 6 показана расчетная величина нормированного потока носителей заряда при комнатной температуре через парный АБ конструкции второго варианта в зависимости от $d_{s p}$. Как видно, при использовании спейсера толщиной 14-20 нм поток электронов снижается дополнительно примерно в 2 раза по сравнению со случаем спейсерного слоя, согласованного по параметру кристаллической решетки с подложкой, что соответствует снижению электронного тока примерно в 4 раза по сравнению со случаем использования одиночного АБ реперной конструкции. Подавление электронного тока через парный АБ связано в данном случае как с эффектом подавления туннелирования электронов через парный потенциальный барьер, так и с возможностью увеличения толщины каждого из АБ слоев за счет компенсации упругих напряжений с помощью спейсера. При этом поток дырок практически не изменяется.

\section{4. Заключение}

Таким образом, нами был рассмотрен подход к подавлению паразитной рекомбинации в волноводных слоях лазерных гетероструктур, заключающийся в использовании парных асимметричных барьерных слоев, разделенных спейсером и прилегающих к активной области по обе стороны. На основе расчетов показано, что парные асимметричные барьеры позволяют в большей степени блокировать нежелательный выброс носителей из активной области в сравнении со случаем одиночных асимметричных барьеров. Это обусловлено, вопервых, возможностью управлять разрешенным спектром носителей и соответственно пропусканием сквозь конструкцию парных асимметричных барьеров за счет квантования состояний в спейсерном слое; во-вторых, тем, что могут быть созданы более толстые и(или) более высокие барьеры благодаря синтезу спейсера, компенсирующего упругие напряжения, вносимые слоями асимметричных барьеров. Предложено два варианта парных асимметричных барьерных слоев, направленных на подавление потока электронов в волноводе $\mathrm{Al}_{0.2} \mathrm{Ga}_{0.8} \mathrm{As}$, которые могут быть синтезированы в псевдоморфном режиме. Первая конструкция с ненапряженным спейсером, вторая - с напряженным спейсером позволяют снизить поток электронов в 2 и 4 раза соответственно в сравнении с реперным одиночным асимметричным барьером.

Работа выполнена при поддержке Российского научного фонда (проект 14-42-00006-П „Новый тип полупроводниковых лазеров с характеристиками, улучшенными за счет использования асимметричных барьеров“").

\section{Список литературы}

[1] Н.А. Пихтин, А.В. Лютецкий, Д.Н. Николаев, С.О. Слипченко, 3.Н. Соколова, В.В. Шамахов, И.С. Шашкин, А.Д. Бондарев, Л.С. Вавилова, И.С. Тарасов. ФТП, 48 (10), 1377 (2014).

[2] И.С. Шашкин, Д.А. Винокуров, А.В. Лютецкий, Д.Н. Николаев, Н.А. Пихтин, М.Г. Растегаева, 3.Н. Соколова, С.О. Слипченко, А.Л. Станкевич, В.В. Шамахов, Д.А. Веселов, А.Д. Бондарев, И.С. Тарасов. ФТП, $46(9), 1230$ (2012).

[3] И.С. Шашкин, Д.А. Винокуров, А.В. Лютецкий, Д.Н. Николаев, Н.А. Пихтин, Н.А. Рудова, 3.Н. Соколова, С.О. Слипченко, А.Л. Станкевич, В.В. Шамахов, Д.А. Веселов, К.В. Бахвалов, И.С. Тарасов. ФТП, 46 (9), 1234 (2012).

[4] Н.А. Пихтин, С.О. Слипченко, И.С. Шашкин, М.А. Ладугин, А.А. Мармалюк, А.А. Подоскин, И.С. Тарасов. ФТП, $44(10), 1411$ (2010).

[5] Д.А. Веселов, И.С. Шашкин, К.В. Бахвалов, А.В. Лютецкий, Н.А. Пихтин, М.Г. Растегаева, С.О. Слипченко, Е.А. Бечвай, В.А. Стрелец, В.В. Шамахов, И.С. Тарасов. ФТП, 50 (9), 1247 (2016).

[6] H. Kurakake, T. Uchida, T. Yamamoto, T. Higashi, S. Ogita, M. Kobayashi. IEEE J. Select. Topics Quant. Electron., 3 (2), 632 (1997).

[7] L.V. Asryan, S. Luryi. Sol. St. Electron., 47 (2), 205 (2003).

[8] L.V. Asryan, N.V. Kryzhanovskaya, M.V. Maximov, A.Yu. Egorov, A.E. Zhukov. Semicond. Sci. Technol., 26 (5), 055025 (2011).

[9] А.Е. Жуков, Н.В. Крыжановская, М.В. Максимов, А.Ю. Егоров, М.М. Павлов, Ф.И. Зубов, Л.В. Асрян. ФТП, 45 (4), 540 (2011).

[10] L.V. Asryan, N.V. Kryzhanovskaya, M.V. Maximov, F.I. Zubov, A.E. Zhukov. J. Appl. Phys., 114, 143103 (2013). 
[11] A.E. Zhukov, N.V. Kryzhanovskaya, F.I. Zubov, Y.M. Shernyakov, M.V. Maximov, E.S. Semenova, K. Yvind, L.V. Asryan. Appl. Phys. Lett., 100 (2), 021107 (2012).

[12] F.I. Zubov, M.V. Maximov, Yu.M. Shernyakov, N.V. Kryzhanovskaya, E.S. Semenova, K. Yvind, L.V. Asryan, A.E. Zhukov. Electron. Lett., 51 (14), 1106 (2015).

[13] А.Е. Жуков, Л.В. Асрян, Е.С. Семенова, Ф.Е. Зубов, Н.В. Крыжановская, М.В. Максимов. ФТП, 49 (7), 956 (2015).

[14] Л.В. Асрян, Ф.И. Зубов, Н.В. Крыжановская, М.В. Максимов, А.Е. Жуков. ФТП, 50 (10), 1380 (2016).

[15] Ю.С. Полубавкина, Ф.И. Зубов, Э.И. Моисеев, Н.В. Крыжановская, М.В. Максимов, Е.С. Семенова, К. Yvind, Л.В. Асрян, А.Е. Жуков. ФТП, 51 (2), 263 (2017).

[16] R. Tsu, L. Esaki. Appl. Phys. Lett., 22 (11), 562 (1973).

[17] J.W. Matthews, A.E. Blakeslee. J. Cryst. Growth, 27, 118 (1974).

Редактор Г.А. Оганесян

\section{Suppression of waveguide recombination by means of double asymmetric barriers in laser heterostructures}

F.I. Zubov' ${ }^{1}$, M.V. Maximov ${ }^{1,2}$, N.Yu. Gordeev ${ }^{2,1}$, Yu.S. Polubavkina ${ }^{1}$, A.E. Zhukov ${ }^{1}$

${ }^{1}$ St. Petersburg Academic University, 194021 St. Petersburg, Russia

${ }^{2}$ Ioffe Institute,

194021 St. Petersburg, Russia

Abstract A semiconductor laser design is proposed in which parasitic waveguide recombination is suppressed by means of a pair of asymmetric barriers adjacent to the active region. The pair of asymmetric barriers blocks the undesired transport of one type of charge carriers, not preventing transport of another type of carriers. Spacer separating the pair of asymmetric barriers can serve to compensate the elastic strain introduced by them as well as to control the energy spectrum of the charge carriers and consequently the transmission coefficient. Using an example of a laser with an $\mathrm{Al}_{0.2} \mathrm{Ga}_{0.8}$ As waveguide, it is shown that by utilization of the double asymmetric barriers design the undesired electron transport can be suppressed by a factor of 4 in comparison with the case of using of a single asymmetric barrier. 